\title{
A new grading system for evaluation of uroflowmetry-EMG results (Gülhane Grading System)
}

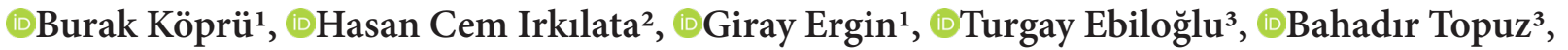

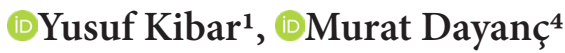 \\ ${ }^{1}$ Koru Ankara Hospital, Urology Clinic, Ankara, Turkey \\ ${ }^{2}$ Isparta Private Davraz Life Hospital, Urology Clinic, Isparta, Turkey \\ ${ }^{3}$ Gülhane Training and Research Hospital, Department of Urology, Ankara, Turkey \\ ${ }^{4}$ Private Pediatric Urology Center, Ankara, Turkey
}

Cite this article as: Köprü B, Irkılata HC, Ergin G, et al. A new grading system for evaluation of uroflowmetry-EMG results (Gülhane Grading System). Anatolian Curr Med J 2021; 3(3); 227-233.

\begin{abstract}
Aim: It is recommended that dysfunctional voiding diagnosis should made by the repeated uroflowmetry simultaneously pelvic floor electromyography (UF-EMG) + post-void residual measurements. However, there is no evaluation system for UFEMG parameters regarding the clinical diagnosis, follow up and treatment of these patients. In our study, we aimed to create a new grading system for the diagnosis of dysfunctional voiding by using UF-EMG parameters.

Material and Method: We have retrospectively obtained UF-EMG and lower urinary tract symptom score results that performed to the children whom applied to our clinic with the symptoms of dysfunctional voiding between 2010 and 2015 . A total of 856 reports were included into this retrospective cohort analysis. The proper 610 UF-EMG tests were graded according to our grading system. The UF-EMG grading system is divided into 6 grades: Grade 0: No EMG activity and normal uroflowmetry, Gradenon-EMG: Disturbed flow pattern with no EMG activity, Grade 1: EMG activity with no disturbed flow pattern, Grade 2: EMG activity with minimally disturbed flow pattern, Grade 3: EMG activity with moderately disturbed flow pattern, Grade 4: EMG activity with extremely disturbed flow pattern.

Results: There was no statistically significant difference between the demographic data of patient and control groups ( $\mathrm{p}>0.05$ ). According to grading system, day and nighttime incontinence were statistically significant increases as the grades increases (respectively, $\mathrm{p}<0,001, \mathrm{p}=0,023$ ). According to grading system we created as the grades increased the UF-EMG parameters and the questions of lower urinary tract dysfunction symptom score which evaluated the voiding phase results were statistically significant $(\mathrm{p}<0.05)$.
\end{abstract}

Conclusion: Grading system will be helpful to interpreting the results of the UF-EMG, which considered to be relatively difficult and thus, the diagnosis of the patients can be easier to evaluate and respond to the treatment by urologist.

Keywords: Lower urinary tract dysfunction, dysfunctional voiding, uroflowmetry-EMG, grading system

\section{INTRODUCTION}

Dysfunctional voiding (DV) is defined as habitually contractions of the external urethral sphincter during urination in children (1). Formerly, obtaining staccato patterns at repeated uroflowmetry (UF) tests or invasive urodynamic investigation were suggested for the diagnosis of DV (2.3). However, recent guidelines have suggested to perform repeated UF and electromyography (EMG) of pelvic floor muscles (UF-EMG) for the diagnosis and follow-up of DV which also led us to move away from invasive techniques for the evaluation of lower urinary tract dysfunction (LUTD) (4-6).
Uroflowmetry is a simple and non-invasive test which evaluates the voiding phase of lower urinary tract (LUT). The integration of UF results with pelvic floor EMG recordings increases the adequacy of DV diagnosis (35). Several nomograms were defined by using UF rates according to gender among healthy children, which aimed to establish normal UF references $(7,8)$.

UF-EMG has already been proven as a reliable method for the diagnosis of the voiding disorders in children $(4-6,9)$. The flow curve pattern, UF parameters and pelvic floor activity during voiding can concomitantly be evaluated 
by UF-EMG. However, there is no definitive nomogram that leads to stages for voiding dysfunction by UF-EMG findings. The aim of this study to develop a new simple, understandable grading system [Gülhane Grading System (GGS)] which might lead us to reach easy decision of therapies for DV based on the data of EMG activities among 610 patients who performed UF-EMG.

\section{MATERIAL AND METHOD}

This retrospective study was approved by the Ethical Committee of Gülhane Military Medical Academy (Date: September 2012, Decision No: 1491-9912/1648.4-4950) and followed the Institution's Review Board of Human Subject Guidelines. All procedures were carried out in accordance with the ethical rules and the principles of the Declaration of Helsinki. We have retrospectively obtained a total of 856 UF-EMG tests performed children without any neurological or anatomical deficit between September 2010 to October 2015. All performed UF-EMG studies were analyzed by two different pediatric urologists. Children with LUTS were evaluated by lower urinary tract dysfunction symptom score (LUTDSS) defined by Akbal et al. (10) along with UF-EMG analysis. The data of the patients including physical examination, 3-day bladder diary, urine analysis, urine culture, urinary ultrasonography, post-void residual urine (PVR) was also obtained.

In our center, standard urotherapy, voiding training, regulation of daily fluid, stay away from colorful liquids (coke, fruit juice etc.) and fiber rich diet for the prevention of constipation were recommended to children with DV.

LUTDSS is a diagnostic tool for the diagnosis of LUTD in children with a score of 8.5 or greater had voiding abnormalities, with $90 \%$ sensitivity and $90 \%$ specifity (10). The questionnaire was composed of the following items: daytime urinary incontinance $(\mathrm{Q} 1,2)$, nighttime urinary incontinance $(\mathrm{Q} 3,4)$, frequency $(\mathrm{Q} 5)$, voiding habits as strain, pain during voiding, intermittency $(\mathrm{Q} 6,7,8,9)$, bladder habits as urgency and urge incontinance $(\mathrm{Q} 10,11,12)$, constipation $(\mathrm{Q} 13)$ and quality of life.

UF-EMG studies were performed by the expert nurse (MMS 5000, Medical measurement system 5000, USA) in our urodinamy study center. In our clinic, all patients were informed about UF-EMG procedure for reduce the anxiety as a routine clinical practice. Bladder volume was assessed by ultrasonography (Bladder Scan BVI 6100, Bothell, WA) to ensure expected bladder capacity (EBC) is enough to perform for UF. EBC was calculated using Koff's formula (11). Superficial surface electrodes used for recording the external sphincter EMG activity were placed at 3 and 9 oclock positions at the perineum and third electrode placed to left thigh. PVR was measured by ultrasonography
(Bladder Scan BVI 6100) immediately after voiding. We have included into our analysis the following parameters recorded by UF-EMG: expected bladder capacity, voided volume (VV), voiding time (VT), average flow rate (Qave), maximum flow rate (Qmax), maximum flow rate time (T-Qmax), EMG activity and PVR.

\section{Gülhane Grading System (GGS)}

The reports with any artefact were not graded. The stratification of EMG activities that reflects the voiding pattern was the key parameter for our new scale.

GGS was defined in to 6 grades as Grade 0: Patients with bell curve type voiding curve and without EMG activity (Figure 1A), Grade 1: EMG activity with not disrupt the voiding curve (Figure 1B), Grade 2: EMG activity that does not disrupt the voiding curve minimally, EMG activity that does not cause deep notches in the voiding curve during voiding (Figure 1C), Grade 3: moderately disrupted voiding curve, patients with EMG activity leading to staccato or plateau type voiding curve (Figure 1D), Grade 4: Patients with EMG activity leading to intermittent voiding curve (Figure 1E), Grade nonEMG: the disrupt voiding curve without EMG or delayed activity was determined (Figure 1F).

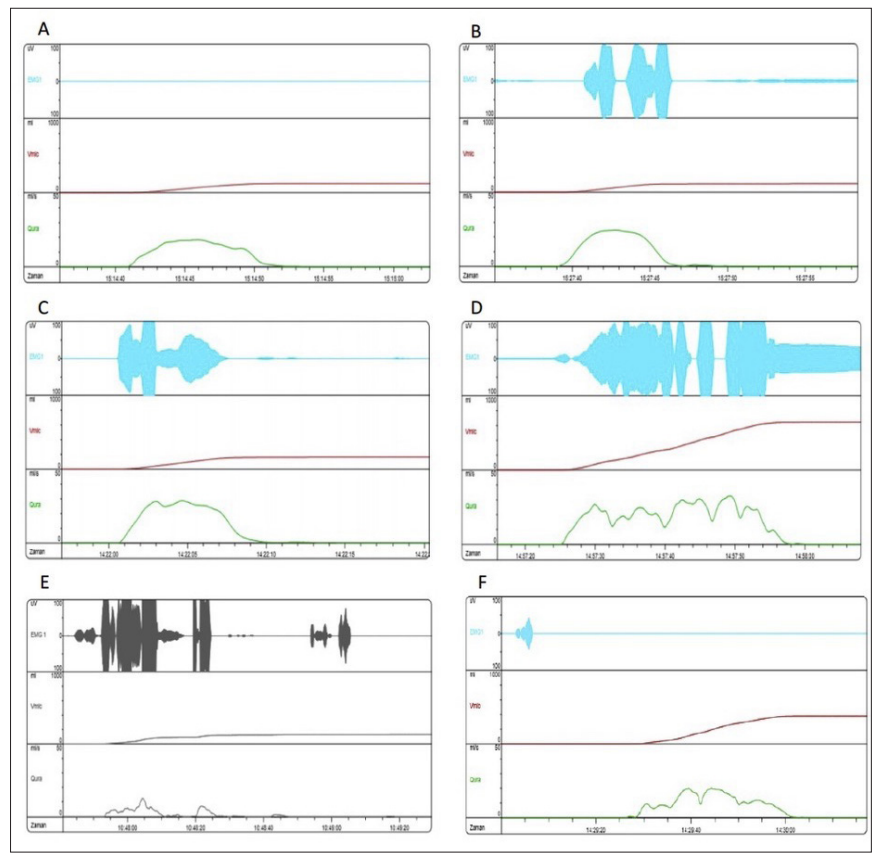

Figure 1. A: Grade 0 UF-EMG sample image according to GGS, B: Grade 1 UF-EMG sample image according to GGS, C: Grade 2 UFEMG sample image according to GGS, D: Grade 3 UF-EMG sample image according to GGS, E: Grade 4 UF-EMG sample image according to GGS, F: Gradenon-EMG UF-EMG sample image according to GGS

After analyzing the reports and demographical data of the patients we have excluded the children with anatomical abnormality, acute or chronic urinary tract infection, urolithiasis, neurologic lesions, chronic constipation and any records with artefacts due to the wet skin or cross talking of the electrodes. Among 729 
reports, a total 610 patient data were included into the statistical analysis (Figure 2). After completion of retrospective data obtaining, we also have performed LUTDSS and UF EMG to 119 healthy children to demonstrate the normal values of UF-EMG.

The children with any LUTS and LUTDSS $>8.5$ were assigned as patient group, whereas the children with LUTS and LUTDSS score as 0 in control group. Study flow chard was given in Figure 2.

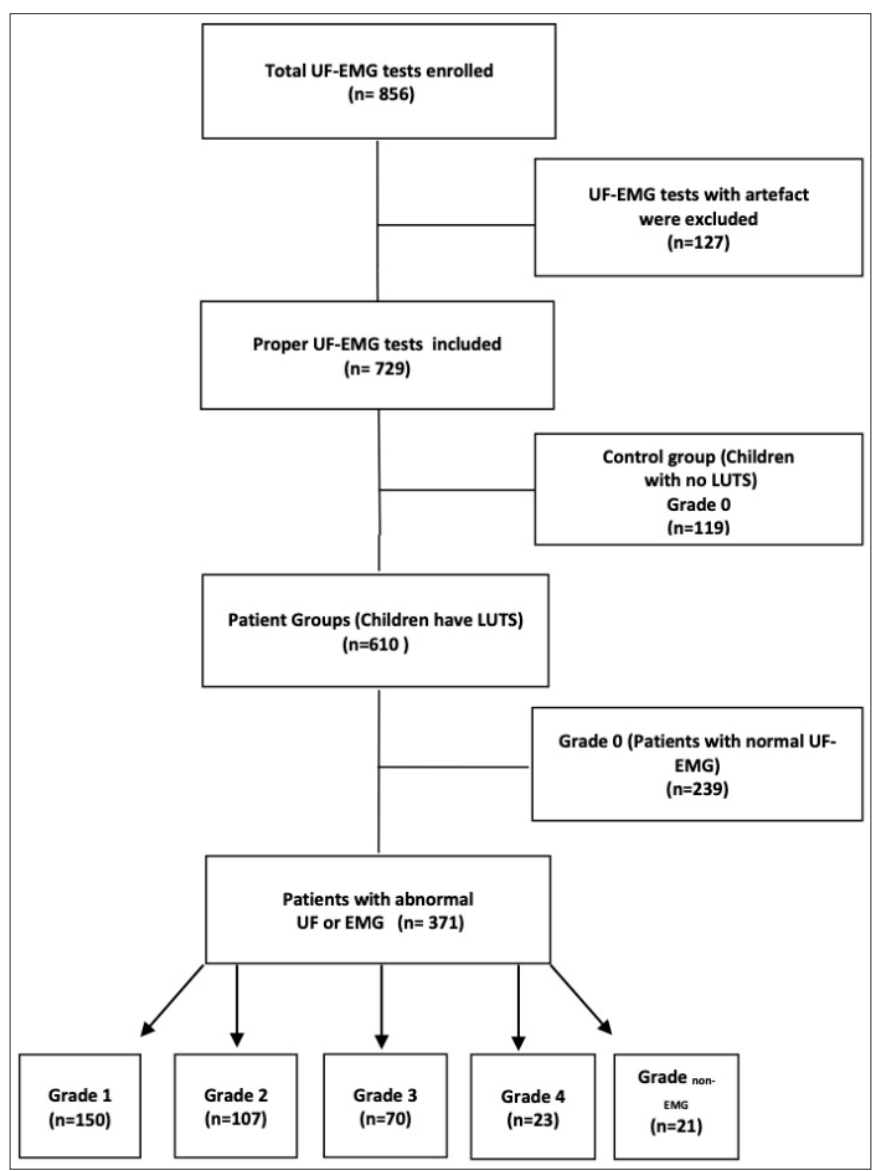

Figure 2. Study flow-chart

\section{Statistical Analysis}

The statistical analysis was using the Statistical Package for Social Sciences 15.0 software (SPSS 15.0 package program, Collage Station, TX, USA). Descriptive statistic was calculate using number, percentage, standard deviation, minimum and maximum as proper. In comparisons between groups, Mann Whitney-U test was used for advanced paired comparisons. Student-T test was used in the comparison of 2 groups. The ChiSquare test was used to compare discrete variables. Log formation was used for the abnormally distributed data for the reach normality. Spearmen Correlation test was used to evaluate the linear relationship between variables. $\mathrm{p}<0.05$ level was considered statistically significant.

\section{RESULTS}

A total 610 UF-EMG (433 female, 177 male) patients and 119 UF-EMG (75 female, 44 male) control $(\mathrm{p}=0.188)$ have been included to our study. The mean age was $8.90 \pm 2.91$ for patient group and $9.02 \pm 2.86$ for control group $(\mathrm{p}=0.168)$. There was no statistically significant difference between patient and control groups regarding age and gender. The analysis of patient and control groups' with GGS grades, mostly grade 0 was detected in the patient group (39\%) and no grade 4 was detected in control group (Table 1).

\section{Table 1. UF-EMG results of the patient and control group} according to GGS

\begin{tabular}{|clcccc|}
\multirow{2}{*}{ Group } & & \multicolumn{2}{c|}{ Patient $(\mathbf{n}=\mathbf{6 1 0})$} & \multicolumn{2}{c|}{ Control $(\mathbf{n = 1 1 9})$} \\
\cline { 3 - 6 } & & $\mathbf{n}$ & $\mathbf{\%}$ & $\mathbf{n}$ & $\mathbf{\%}$ \\
\hline \multirow{5}{*}{ Grade } & 0 & 239 & 39 & 90 & 76 \\
& 1 & 150 & 25 & 17 & 15 \\
& 2 & 107 & 18 & 9 & 7 \\
& 3 & 70 & 12 & 3 & 2 \\
& 4 & 23 & 3.7 & 0 & 0 \\
& non-EMG & 21 & 3.3 & 0 & 0 \\
\hline
\end{tabular}

There was a statistically significant positive correlation between the mean age and GGS grades $(r=0.128, p=0.002)$ and negative correlation between the mean age and LUTDSS total score $(\mathrm{r}=-0.208 \mathrm{p}<0.001)$. The comparison analysis showed that the mean age was sequentially increasing by increase in GGS grades (Table 2). The female patients had statistically significantly higher GGS grades compared to male patients $(\mathrm{p}<0.001)$ (Table 2).

When we further analyzed the LUTDSS questionnaire by GGS scale; there was a statistically significantly increase in presence and the severity of incontinence (Q1, Q2) by increasing GGS grade $(\mathrm{p}<0.001)$. The comparison of nighttime symptom questions (Q3, Q4) showed statistically significant difference by increase in GGS grade $(\mathrm{p}<0.001$ for $\mathrm{Q} 3$ and $\mathrm{P}=0.023$ for $\mathrm{Q} 4)$. No significant difference was found regarding the $\mathrm{Q} 5$ which reflects the voiding frequency of the patient $(\mathrm{p}=0.26)$. The analysis of Q6,7,8,9 that examine the voiding habits and voiding phase, only straining (Q6) and intermittency (Q8) showed statistically significant differences between GGS grades $(\mathrm{p}<0,001)$. The questions that reflect the bladder habits $(\mathrm{Q} 10,11)$ showed no difference by GGS grades except Q12 which indicates bladder storage $(\mathrm{p}=0.016)$. All the results were depicted in Table 3 .

When we analyzed all UF parameters results according to GGS scale, all the parameters showed significant deterioration by GGS grade. The results were summarized in Table 4. The spearmen correlation analysis showed that there was a statistically significant positive correlation between GGS grades and EBC, VV, VT, TQmax and PVR. The Qwave and Qmax values did not show statistically significant correlation with GGS scores (Table 5). 
Table 2. Patients' demographic data and LUTSS questions according to GGS

\begin{tabular}{|c|c|c|c|c|c|c|c|c|c|c|c|c|c|c|}
\hline \multicolumn{2}{|l|}{ Grup } & \multirow{2}{*}{\multicolumn{2}{|c|}{$\begin{array}{c}\begin{array}{c}\text { Grade } \mathbf{0} \\
\mathbf{n}=\mathbf{2 3 9}\end{array} \\
8.29 \pm 2.79 \\
(5-17)\end{array}$}} & \multirow{2}{*}{\multicolumn{2}{|c|}{$\begin{array}{c}\begin{array}{c}\text { Grade } \mathbf{1} \\
\mathbf{n}=\mathbf{1 5 0}\end{array} \\
8.60 \pm 2.82 \\
(5-17)\end{array}$}} & \multirow{2}{*}{\multicolumn{2}{|c|}{$\begin{array}{c}\begin{array}{c}\text { Grade } 2 \\
\mathbf{n}=\mathbf{1 0 7}\end{array} \\
9.41 \pm 3.15 \\
(5-19)\end{array}$}} & \multirow{2}{*}{\multicolumn{2}{|c|}{$\begin{array}{c}\begin{array}{c}\text { Grade } 3 \\
\mathbf{n}=\mathbf{7 0}\end{array} \\
9.58 \pm 2.93 \\
(5-16)\end{array}$}} & \multirow{2}{*}{\multicolumn{2}{|c|}{$\begin{array}{c}\begin{array}{c}\text { Grade } 4 \\
\mathbf{n}=\mathbf{2 3}\end{array} \\
9.78 \pm 2.53 \\
(6-15)\end{array}$}} & \multirow{2}{*}{\multicolumn{2}{|c|}{$\begin{array}{c}\begin{array}{c}\text { Grade non-EMG } \\
\mathbf{n}=\mathbf{2 1}\end{array} \\
9.95 \pm 2.68 \\
(5-17)\end{array}$}} & $\mathbf{p}$ \\
\hline \multirow[t]{2}{*}{ Age } & \multirow[t]{2}{*}{$\begin{array}{l}\text { Mean } \pm \text { SD } \\
(\text { Min-max) }\end{array}$} & & & & & & & & & & & & & 0.012 \\
\hline & & n & $\%$ & $\mathbf{N}$ & $\%$ & n & $\%$ & $\mathbf{n}$ & $\%$ & $\mathbf{n}$ & $\%$ & $\mathbf{n}$ & $\%$ & \\
\hline \multirow{2}{*}{ Gender } & Female & 147 & 61.3 & 105 & 70.1 & 88 & 82.2 & 61 & 87 & 23 & 100 & 12 & 57.1 & \multirow[b]{2}{*}{$<0.001$} \\
\hline & Male & 92 & 38.6 & 45 & 29.9 & 19 & 17.8 & 9 & 13 & 0 & 0 & 9 & 42.8 & \\
\hline \multirow[t]{4}{*}{ LUTSS } & $\begin{array}{l}\text { Mean } \pm \text { SD } \\
(\text { Min-max) }\end{array}$ & \multicolumn{2}{|c|}{$\begin{array}{c}11.04 \pm 6.40 \\
(1-31)\end{array}$} & \multicolumn{2}{|c|}{$\begin{array}{c}12.02 \pm 6.56 \\
(1-33)\end{array}$} & \multicolumn{2}{|c|}{$\begin{array}{c}12.90 \pm 6.78 \\
(1-32)\end{array}$} & \multicolumn{2}{|c|}{$\begin{array}{c}14.31 \pm 6.89 \\
(1-35)\end{array}$} & \multicolumn{2}{|c|}{$\begin{array}{c}14.52 \pm 5.62 \\
(4-27)\end{array}$} & \multicolumn{2}{|c|}{$\begin{array}{c}14.19 \pm 6.21 \\
(5-24)\end{array}$} & 0.50 \\
\hline & Sometimes & 87 & 14.2 & 63 & 10.3 & 37 & 6.6 & 24 & 4.0 & 8 & 1.3 & 11 & 1.8 & \\
\hline & Mostly & 80 & 13.1 & 33 & 5.4 & 39 & 6.4 & 18 & 3.0 & 3 & 0.5 & 7 & 1.1 & \\
\hline & Seriously & 18 & 2.9 & 20 & 3.2 & 7 & 1.1 & 12 & 2.0 & 1 & 0.1 & 2 & 0.3 & \\
\hline
\end{tabular}

\section{Table 3. The Comparison of LUTSS questionnaire by GGS}

Group

No

urinary incontinence

during the day?

Q2: How wet is your

child during the day?

Q3: Does your child have urinary incontinance

during the night?

Q4: How wet is your child during the night?

Q5: How many times does your child void?

Q6: My child has to strain to pee.

Q7: My child feels pain during voiding

Q8: My child pees

intermittently when on
the toilet.

Q9: My child has to go No

to revisit the toilet to pee

soon after his/her pee. Yes

Q10: My child has to run No to the toilet when s/he feels the need to pee. Yes

Q11: My child can hold No his/her pee by crossing his/her legs, squatting, or doing the "pee dance." Yes

Q12: My child wets $\quad$ No his/her clothes before reaching the toilet. Yes

Q13: My child does not No

pass stool every day. Yes

Quality of life:Does this affect his/her family life or social life?

No

\section{Grade 0

$\mathbf{n}=\mathbf{2 3 9}$

Grade 1 $\mathrm{n}=150$

\section{Grade 2 $\mathrm{n}=\mathbf{1 0 7}$}

Grade 3
$\mathbf{n}=70$

G

Grade 4

$\mathrm{n}=23$

Grade nonEMG $n=21$

$\begin{array}{llllllllllll}87 & 14.3 & 57 & 9.3 & 26 & 4.2 & 9 & 1.5 & 3 & 0.4 & 3 & 0.5\end{array}$

$\begin{array}{llllllllllll}114 & 18.8 & 78 & 12.8 & 60 & 9.8 & 41 & 6.7 & 11 & 1.8 & 13 & 2.1\end{array}$

$\begin{array}{llllllllllll}27 & 4.6 & 10 & 1.6 & 7 & 1.1 & 12 & 2.0 & 8 & 1.3 & 5 & 0.8\end{array}$

8

$<0.001$ 1-2 times/day

$\begin{array}{lll}11 & 1.9 \\ 78 & 12.7 & 43\end{array}$

A few drops 78

Only underwear wet

$\begin{array}{lllll}1.9 & 5 & 0.8 & 14 & 2.2\end{array}$

$8 \quad 1.3$ Pants soaking wet

No

$10 \quad 1.6$

$\begin{array}{ll}75 & 12.2\end{array}$

$107 \quad 17.7$

3-5 nights week 6-7 nights/week

$39 \quad 6.4$

$\begin{array}{lllll}18 & 3.0 & 12 & 19.6 & 17\end{array}$
Underwear wet

$\begin{array}{llll}97 & 15.9 & 66 & 10.8\end{array}$

1-7/Day

$\begin{array}{lllll}134 & 21.9 & 93 & 15.2 & 69\end{array}$

More than 7/Day

$\begin{array}{lllll}105 & 17.2 & 57 & 9.4 & 38\end{array}$

$\begin{array}{lllll}203 & 33.2 & 126 & 20.6 & 67\end{array}$

$\begin{array}{lllll}36 & 5.9 & 24 & 3.9 & 40\end{array}$

$\begin{array}{lllll}203 & 32.1 & 120 & 19.6 & 84\end{array}$

$\begin{array}{lllll}36 & 5.9 & 30 & 5.0 & 23\end{array}$

$\begin{array}{llllll}186 & 30.4 & 106 & 17.3 & 63\end{array}$

$\begin{array}{llllll}186 & 30.4 & 106 & 17.3 & 63 & 10.3\end{array}$

$\begin{array}{llllllllllll}53 & 8.6 & 44 & 7.2 & 44 & 7.2 & 29 & 4.8 & 13 & 2.1 & 9 & 1.4\end{array}$

$\begin{array}{llllllllllll}184 & 30.1 & 117 & 19.1 & 83 & 13.6 & 48 & 7.9 & 13 & 2.1 & 16 & 2.6\end{array}$

$\begin{array}{llllllllllll}55 & 9.2 & 33 & 5.4 & 24 & 3.9 & 22 & 3.6 & 10 & 1.6 & 5 & 0.8\end{array}$

$\begin{array}{llllllllllll}53 & 8.8 & 43 & 7.0 & 34 & 5.5 & 20 & 3.2 & 9 & 1.5 & 4 & 0.6\end{array}$

$\begin{array}{llllllllllll}167 & 27.3 & 107 & 17.5 & 73 & 12.0 & 50 & 8.2 & 14 & 2.3 & 17 & 2.8\end{array}$

$\begin{array}{llllllllllll}115 & 18.9 & 85 & 14.0 & 63 & 10.3 & 35 & 5.7 & 14 & 2.3 & 9 & 1.4\end{array}$

$\begin{array}{llllllllllll}124 & 20.3 & 65 & 11.1 & 44 & 7.2 & 35 & 5.7 & 9 & 1.5 & 12 & 2.0\end{array}$

$\begin{array}{llllllllllll}106 & 17.3 & 84 & 13.7 & 69 & 11.3 & 42 & 6.9 & 11 & 1.8 & 11 & 1.8\end{array}$

$\begin{array}{llllllllllll}133 & 21.8 & 66 & 10.8 & 38 & 6.2 & 28 & 4.6 & 12 & 2.0 & 10 & 1.6\end{array}$

$\begin{array}{llllllllllll}196 & 32.2 & 133 & 21.8 & 85 & 14.0 & 49 & 8.0 & 19 & 3.1 & 14 & 2.2\end{array}$

$\begin{array}{llllllllllll}43 & 7.1 & 17 & 2.8 & 22 & 3.6 & 21 & 3.4 & 4 & 0.6 & 7 & 1.1\end{array}$

0.113

$\begin{array}{llllllllllll}54 & 9.0 & 34 & 5.5 & 24 & 4.0 & 16 & 2.6 & 11 & 1.8 & 1 & 0.01\end{array}$

$\begin{array}{llllllllllll}87 & 14.2 & 63 & 10.3 & 37 & 6.6 & 24 & 4.0 & 8 & 1.3 & 11 & 1.8\end{array}$

$\begin{array}{llllllllllll}80 & 13.1 & 33 & 5.4 & 39 & 6.4 & 18 & 3.0 & 3 & 0.5 & 7 & 1.1\end{array}$

0.011 


\begin{tabular}{|c|c|c|c|c|c|c|c|c|}
\hline Group & & $\begin{array}{c}\text { Grade } 0 \\
\mathrm{n}=239\end{array}$ & $\begin{array}{c}\text { Grade } 1 \\
n=150\end{array}$ & $\begin{array}{c}\text { Grade } 2 \\
\mathbf{n}=107\end{array}$ & $\begin{array}{c}\text { Grade } 3 \\
n=70\end{array}$ & $\begin{array}{c}\text { Grade } 4 \\
n=23\end{array}$ & $\begin{array}{l}\text { Gradenon- } \\
\text { EMG n=21 }\end{array}$ & $\mathbf{P}$ \\
\hline $\mathrm{EBC}(\mathrm{ml})$ & $\begin{array}{l}\text { Mean } \pm \text { SD } \\
\text { (Min-max) }\end{array}$ & $\begin{array}{c}287.85 \pm 83.93 \\
(150-540)\end{array}$ & $\begin{array}{c}288.2 \pm 84.77 \\
(180-540)\end{array}$ & $\begin{array}{c}312.33 \pm 94.77 \\
(180-600)\end{array}$ & $\begin{array}{c}317.57 \pm 88.09 \\
(180-510)\end{array}$ & $\begin{array}{c}323.47 \pm 76.19 \\
(210-480)\end{array}$ & $\begin{array}{c}328.57 \pm 81.22 \\
(210-540)\end{array}$ & 0.012 \\
\hline $\mathrm{VV}(\mathrm{ml})$ & $\begin{array}{l}\text { Mean } \pm \text { SD } \\
(\text { Min-max) }\end{array}$ & $\begin{array}{c}195.80 \pm 167 \\
(36-660)\end{array}$ & $\begin{array}{c}195.62 \pm 104.00 \\
(43-530)\end{array}$ & $\begin{array}{c}261.90 \pm 171.33 \\
(30-980)\end{array}$ & $\begin{array}{c}315.44 \pm 203.31 \\
\quad(75-1100)\end{array}$ & $\begin{array}{c}269.43 \pm 151.43 \\
(55-571)\end{array}$ & $\begin{array}{c}320.52 \pm 98.56 \\
(122-660)\end{array}$ & $<0.001$ \\
\hline VT (sec) & $\begin{array}{l}\text { Mean } \pm \text { SD } \\
\text { (Min-max) }\end{array}$ & $\begin{array}{c}18.18 \pm 13.6 \\
(6-108)\end{array}$ & $\begin{array}{c}19.64 \pm 10.71 \\
(7-77)\end{array}$ & $\begin{array}{c}25.84 \pm 22.56 \\
(8-231)\end{array}$ & $\begin{array}{c}29.32 \pm 11.46 \\
(11-57)\end{array}$ & $\begin{array}{c}48.43 \pm 25.99 \\
(14-116)\end{array}$ & $\begin{array}{c}33.52 \pm 11.32 \\
(13-57)\end{array}$ & $<0.001$ \\
\hline $\begin{array}{l}\text { Qave (ml/ } \\
\mathrm{sec})\end{array}$ & $\begin{array}{l}\text { Mean } \pm \text { SD } \\
(\text { Min-max) }\end{array}$ & $\begin{array}{c}13.95 \pm 4.68 \\
(5-30)\end{array}$ & $\begin{array}{c}12.35 \pm 4.45 \\
(5-25)\end{array}$ & $\begin{array}{c}11.24 \pm 6.20 \\
(4.33)\end{array}$ & $\begin{array}{c}10.72 \pm 4.37 \\
(3-21)\end{array}$ & $\begin{array}{c}6.82 \pm 3.33 \\
(3-16)\end{array}$ & $\begin{array}{c}11.61 \pm 5.57 \\
(6-18)\end{array}$ & $<0.001$ \\
\hline $\begin{array}{l}\text { Qmax (ml/ } \\
\mathrm{sec})\end{array}$ & $\begin{array}{l}\text { Mean } \pm \text { SD } \\
\text { (Min-max) }\end{array}$ & $\begin{array}{c}21.9 \pm 9.57 \\
(8-57)\end{array}$ & $\begin{array}{c}22.31 \pm 9.84 \\
(5-66)\end{array}$ & $\begin{array}{c}24.55 \pm 11.48 \\
(3-62)\end{array}$ & $\begin{array}{c}25.02 \pm 9.55 \\
(7-48)\end{array}$ & $\begin{array}{c}17.52 \pm 7.82 \\
(7-33)\end{array}$ & $\begin{array}{c}26.52 \pm 6.45 \\
(16-48)\end{array}$ & 0.002 \\
\hline $\begin{array}{l}\text { T-Qmax } \\
\text { (sec) }\end{array}$ & $\begin{array}{l}\text { Mean } \pm \text { SD } \\
\text { (Min-max) }\end{array}$ & $\begin{array}{c}6.80 \pm 6.06 \\
(1-65)\end{array}$ & $\begin{array}{c}6.19 \pm 4.48 \\
(1-27)\end{array}$ & $\begin{array}{c}8.35 \pm 5.92 \\
(2-37)\end{array}$ & $\begin{array}{c}9.55 \pm 5.87 \\
(1-38)\end{array}$ & $\begin{array}{c}22.00 \pm 37.23 \\
(2-172)\end{array}$ & $\begin{array}{c}9.61 \pm 5.68 \\
(4-26)\end{array}$ & $<0.001$ \\
\hline PVR (ml) & $\begin{array}{l}\text { Mean } \pm \text { SD } \\
(\text { Min-max) }\end{array}$ & $\begin{array}{c}22.98 \pm 15.50 \\
(0-225)\end{array}$ & $\begin{array}{c}21.92 \pm 11.62 \\
(0-190)\end{array}$ & $\begin{array}{c}42.85 \pm 19.02 \\
(0-339)\end{array}$ & $\begin{array}{c}54.52 \pm 15.91 \\
(0-277)\end{array}$ & $\begin{array}{c}64.95 \pm 20.60 \\
(0-142)\end{array}$ & $\begin{array}{c}60.04 \pm 12.36 \\
(0-225)\end{array}$ & $<0.001$ \\
\hline
\end{tabular}

Table 5. The statistical correlation between grades and UF-EMG parameters

\begin{tabular}{|c|c|c|c|c|c|c|c|c|}
\hline & & EBC & VV & VT & Qvave & Qmax & T-Qmax & PVR \\
\hline \multirow{2}{*}{ GGS Grade } & $r^{*}$ & 0.140 & 0.261 & 0.288 & -0.016 & 0.05 & 0.227 & 0.117 \\
\hline & $\mathrm{p}^{*}$ & 0.001 & $<0.001$ & $<0.001$ & 0.697 & 0.216 & $<0.001$ & 0.004 \\
\hline
\end{tabular}

\section{DISCUSSION}

Uroflowmetry is the main important evaluation test that analysis the voiding phase of LUT. Simultaneous assessment of UF with pelvic floor EMG along with PVR test gives much valuable information about LUTD diagnosis and severity (4). The aim of this study was to create a new simple grading system depends on UF-EMG findings by the presence of EMG activity for to determine the severity of DV.

LUTDSS is a non-invasive questionnaire including the day and night incontinence with filling-phase symptoms and voiding-phase symptoms (10). In our study, there was no significant differences between GGS grades regarding LUTDSS, although correlation showed mild significance. This result led us to suggest that LUTDSS evaluates the voiding and storage phase of bladder at the same time, however GGS was designed according to UF-EMG test which evaluate the voiding phase of bladder.

The bell-shaped curve defined in healthy child is regardless from gender, age and voided volume (6). In our study, the most common patient group was grade 0 patients with a bell-shaped curve. Although the LUTDSS of those patients was higher than 8.5, their UF-EMG findings were similar with the control group. Samijn et al. (12) reported $50-60 \%$ of children with LUTS void on the bell-shaped curve and suggested that initiation to the procedure with a UF alone and followed by a measurement of UF with EMG. Similar with this study, we have found the rate of Grade 0 and Grade 1 which were bell shaped curve in $54 \%$ of the patient.
This complex situation might be due to the incorrect interpretation of LUTDSS questions by families of the patients whom might have nocturnal enuresis. Nocturnal enuresis is common clinical disorder which has primary or mono symptomatic types and has a deep impact on affected children and their families $(13,14)$. Furthermore, repeated UF-EMG tests in those patients would help to make the definitive diagnosis.

The urgency symptom is a predominant symptom in the overactive bladder and a silent pelvic floor or minimal EMG activity during voiding, which does not affect the voiding curve is a guide for the diagnosis of overactive bladder in children $(2,15)$. In our study, the incidence of urgency symptom (Q10) decreased as the grades increased. That results might be due to the low grade GGS patients have more profoundly overactive bladder also GGS gives information about the voiding phase.

ICCS suggested that to perfom repeated UF-EMG tests for the diagnosis of DV. Mostly, in DV uroflow pattern show staccato pattern and interrupted pattern with EMG activity due to the lack of the sphincter relaxation during voiding (16).

A staccato or fluctuating uroflow pattern is considered representative for DV. Additionally, interrupted-shaped flow pattern might be seen in patients with DV. Wenske et al. (17) reported that staccato or interrupted flow curve was associated with a $40.7 \%$ incidence of an active pelvic floor EMG during voiding at DV. In this study, the rate of DV is $41.6 \%$ among only staccato pattern. 
Remaining $59.3 \%$ of patients with staccato, interrupted or mixed uroflow pattern had a quiet pelvic floor EMG during voiding. These patients were ultimately diagnosed as primary bladder neck dysfunction (PBND) in $27.9 \%$, detrusor underactivity in $15.2 \%$, and idiopathic detrusor overactivity disorder in $16.1 \%$. Therefore, majority of staccato or interrupted flow patterns were not associated with DV in this study (17). According to them, EMG positivity during voiding is vital for the diagnosis of DV. Increased pelvic floor muscle activity can cause staccato or interrupted, and sometimes depressive (plateau-like) voiding patterns. Rarely, a bell voiding pattern might be seen during positive EMG. We believe that the most of Grade 3 patients have DV and Grade 4 patients have DV with under active bladder.

PBND is a disease characterized by weak voiding flow due to delay or incomplete opening of the bladder neck during voiding. The EMG lag time is defined in the UFEMG test is also a peciluar finding to $\operatorname{PBND}(6,9,18)$. Plateau voiding flow is a low-amplitude voiding pattern due to the bladder outlet obstruction and in UF-EMG mostly does nothave EMG activation during voiding (6). Taken all these together, Gradenon-emg indicates the primary bladder neck dysfunction and bladder outlet obstruction in patient groups.

The abnormal contractions of sphincter during voiding could lead to negative effect on uroflowmetry parameters like Qave, VT, Qmax, T-Qmax and PVR. The contracts of external urethral sphincter during voiding causes decrement in Qave, Qmax and increment in VT, T-Qmax and PVR.

In our study we have found the statistically significant decrease in Qave and increase in VT, Qmax, T-Qmax and PVR by GGS grades. Also, the mean age of patients showed statistically significant increase with increasing of grades. We also determined the statistically significant increases of EBC and VV by GGS grades. We believed that the increment of Qmax along with the increase in grades depends on this situation because in DV we expected decreases of Qmax while increase the severity of disease. The positive correlation between UF parameters and GGS finding is supportive for the conclusion regarding increasing grade of GGS is reflective for severity of LUTD.

Dysfunctional voiding is more common and has severe clinical manifestation in females $(19,20)$ then males. In our study, girls showed a statistically significant higher grade of GGS.

Here, this new grading system developed by the presence of EMG activity of UF-EMG test which performed in the initial evaluation of the DV might be very informative for the diagnosis of severity of the disease and decision of treatment type. We believe that the easy interpretation of
UF-EMG results with our new grading system provides clear and effortless practice at outpatient urology clinics.

The main limitations of our study are the retrospective design and single center analysis which limits the generalization of the data. Our findings might shed light on the future larger sample sized, prospective validation studies.

\section{CONCLUSION}

For both diagnosis and follow-up of DV is a complex and our new GGS grading system is easy technique in this field for routine urology practice.

\section{ETHICAL DECLARATIONS}

Ethics Committee Approval: Ethics committee approval was received for this study from the ethics committee of Gülhane Military Medical Academy (Date: September 2012, Decision No: 1491-99-12/1648.4-4950).

Informed Consent: Because the study was designed retrospectively, no written informed consent form was obtained from patients.

Referee Evaluation Process: Externally peer-reviewed.

Conflict of Interest Statement: The authors have no conflicts of interest to declare.

Financial Disclosure: The authors declared that this study has received no financial support.

Author Contributions: All of the authors declare that they have all participated in the design, execution, and analysis of the paper, and that they have approved the final version.

\section{REFERENCES}

1. Wenke S, Van Batavia JP, Combs AJ, Glassberg KI. Analysis of uroflow patterns in children with dysfunctional voiding. J Pediatr Urol 2014; 10: 250-4.

2. Norgaard JP, van Gool JD, Hjalmas K, Djurhuus JC, Hellstrom AL. Standardization and definitions in lower urinary tract dysfunction in children. International Children's Continence Society. Br J Urol 1998; 81: 1-16.

3. Neveus T, von Gontard A, Hoebeke P, et al. The standardization of terminology of lower urinary tract function in children and adolescents: report from the Standardisation Committee of the International Children's Continence Society. J Urol 2006; 176: 314-24.

4. Austin PF, Bauer SB, Bower W, et al. The standardization of terminology of lower urinary tract function in children and adolescents: update report from the Standardization Committee of the International Children's Continence Society. J Urol 2014; 191: 1863-5.

5. Chase J, Austin P, Hoebeke P, McKenna P. The management of dysfunctional voiding in children: a report from the Standardisation Committee of the International Children's Continence Society. J Urol 2010; 183: 1296-302. 
6. Austin PF, Bauer SB, Bower W, et al. The standardization of terminology of lower urinary tract function in children and adolescents: Update report from the standardization committee of the International Children's Continence Society Neurourol Urodyn 2016; 35: 471-81.

7. Kajbafzadeh AM, Yazdi CA, Rouhi O, Tajik P, Mohseni P. Uroflowmetry nomogram in Iranian children aged 7 to 14 years. BMC Urol 2005; 16: 5-3.

8. Gupta DK, Sankhwar SN, Goel A. Uroflowmetry nomograms for healthy children 5 to 15 years old. J Urol 2013; 190: 1008-13.

9. Combs AJ, Grafstein N, Horowitz M, Glassberg KI. Primary bladder neck dysfunction in children and adolescents I: pelvic floor electromyography lag time--a new noninvasive method to screen for and monitor therapeutic response. J Urol 2005; 173: 207-10

10. Akbal C, Genc Y, Burgu B, Ozden E, Tekgul S. Dysfunctional voiding and incontinence scoring system: quantitative evaluation of incontinence symptoms in pediatric population. J Urol 2005; 173: 969-73.

11. Koff SA. Estimating bladder capacity in children. Urology 1983; 21: 248 .

12. Samijn B, Van Laecke E, Vande Walle J, et al. Uroflw measurement combined with electromyography testing of the pelvic floor in healthy children. Neurourol Urodid 2019; 38: 231-8.

13. Kılıç A, Hacıhamdioğlu DÖ, Tural E, Karademir F. Evaluation of neuropsychological development of children diagnosed with primary monosymptomatic nocturnal enuresis: A pilot study. Turk J Urol 2020; 46: 320-5

14. Ferrara P, Franceschini G, Mercurio S, Del Vescovo E, Ianniello F, Petitti T. The adverse effects of oral desmopressin lyophilisate (MELT): personal experience on enuretic children. Turk J Urol 2018; 44: 51-5.

15. Abrams P, Cardoso L, Fall M, et al. The standardization of terminology in lower urinary tract function: report from the standardisation subcommittee of the International Continence Society. Urology 2003; 61: 37-49

16. Sinha S. Dysfunctional voiding: A review of the terminology, presentation, evaluation and management in children and adults. Indian J Urol 2011; 27: 437-47.

17. Wenske S, Combs AJ, Van Batavia JP, et al. Can staccato and interrupted/fractionated uroflow patterns alone correctly identify the underlying lower urinary tract condition? J Urol 2012; 187: 2188-93.

18. Sharifi-Rad L, Seyedian SL, Fatemi-Behbahani SM, Lotfi B, Kajbafzadeh A. Impact of transcutaneous interferential electrical stimulation for management of primary bladder neck dysfunction in children J Pediatr Urol 2020; 16: 36.

19. Corcos J, Schick E. Prevelence of overactive bladder and incontinence in Canada. Can J Urol 2004; 11: 2278-84.

20. Ergin G, Kibar Y, Ebiloğlu T, et al. The role of urinary nerve growth factor for the diagnosis and assessment of the biofeedback success in children with dysfunctional voiding. J Pediatr Urol 2016; $12: 118$ 